\title{
PENGEMBANGAN SISTEM PENDUKUNG KEPUTUSAN PENENTUAN KONSENTRASI BIDANG KEAHLIAN MAHASISWA DENGAN INTEREST INVENTORY
}

\author{
Elin Haerani ${ }^{1}$, Kasman Rukun ${ }^{2}$, Fahmi Rizal ${ }^{3}$ \\ ${ }^{1}$ Teknik Informatika, Fakultas Sains dan Teknologi, Universitas Islam Negeri \\ Sultan Syarif Kasim Riau \\ ${ }^{2,3}$ Pendidikan Teknologi Kejuruan, Fakultas Teknik, Universitas Negeri Padang \\ 1elin.haerani@uin-suska.ac.id, ${ }^{2}$ kasman.rukun@unp.ac.id, ${ }^{3}$ fahmi.rizal@unp.ac.id
}

\begin{abstract}
Universities are designed to prepare graduates who are ready to enter the workforce and are able to develop a professional attitude. Educational institutions such as the University need a form of decisions in determining the right concentration for students, so that the learning process can be achieved well. The decision is very influential on the process of handling the choice of alternative concentration, choosing an appropriate concentration of interest will also have an impact on the research focus for the final assignment of students. This research develops student concentration selection system in Electrical. Currently the concentration determination system is based only on academic assessment alone, regardless of student interest, so that it can impact on student learning outcomes. The system was developed by combining academic judgment and interest inventory with three criteria, ie, interest tests using interest inventory, prerequisite concentration course grades, and GPA. The system is built using an intelligent system model that is Fuzzy Multiple Attribute Decision Making (FMADM), which helps the Department in the selection process and helps the process of career guidance on students. With this selection system, the Department can be provide the most suitable concentration decisions with interest in student.
\end{abstract}

Keywords: Interest, Decision Support System, FMADM

\begin{abstract}
ABSTRAK
Universitas dirancang untuk mempersiapkan lulusan yang siap memasuki dunia kerja dan mampu mengembangkan sikap profesional. Institusi pendidikan seperti Universitas membutuhkan bentuk keputusan dalam menentukan konsentrasi yang tepat bagi mahasiswa, sehingga proses pembelajaran dapat tercapai dengan baik. Keputusan ini sangat berpengaruh pada proses penanganan pilihan konsentrasi bidang keahlian, memilih konsentrasi yang sesuai minat juga akan berdampak pada fokus penelitian untuk tugas akhir mahasiswa. Penelitian ini mengembangkan sistem pemilihan konsentrasi mahasiswa di bidang elektronika. Saat ini sistem penentuan konsentrasi hanya didasarkan pada penilaian akademik saja, tidak berdasarkan dari minat mahasiswa, sehingga dapat berdampak pada hasil belajar. Sistem ini dikembangkan dengan menggabungkan penilaian akademik dan interest inventory dengan tiga kriteria, yaitu, tes minat menggunakan interest inventory, mata kuliah prasyarat, dan IPK. Sistem ini dibangun menggunakan model sistem cerdas yaitu Fuzzy Multiple Attribute Decision Making (FMADM), yang membantu program studi dalam proses penentuan konsentari dan membantu proses bimbingan karir pada mahasiswa. Sistem ini memberikan keputusan konsentrasi yang paling sesuai dengan minat pada mahasiswa.
\end{abstract}

Kata Kunci: Minat, Sistem Pendukung Keputusan, FMADM 


\section{PENDAHULUAN}

Minat adalah sumber motivasi yang mendorong seseorang untuk melakukan apa yang diinginkannya jika orang tersebut diberi kebebasan untuk memilih [1]. Minat juga merupakan kecenderungan perilaku umum seseorang untuk tertarik pada kelompok hal tertentu [2]. Konsep minat dan implikasinya untuk pembelajaran dan pengembangan manusia memiliki peran penting dalam pendidikan [3]. Keterlibatan antara minat dan pembelajaran mahasiswa dapat dijadikan referensi sebagai motivator dalam meningkatkan keterampilan mahasiswa dalam proses pembelajaran [4]. Mengembangkan minat bertujuan agar orang belajar dengan baik dan di masa depan dapat bekerja di bidang yang sesuai dengan kemampuan dan minat mereka sehingga mereka dapat mengembangkan kemampuan untuk belajar dan bekerja secara optimal dengan antusiasme yang tinggi.

Universitas adalah bagian dari pendidikan kejuruan yang dikembangkan di Indonesia, dirancang untuk mempersiapkan mahasiswa atau lulusan yang siap memasuki dunia kerja dan mampu mengembangkan sikap profesional di bidang kejuruan. Lulusan universitas, diharapkan menjadi individu produktif yang mampu bekerja sebagai tenaga kerja dan memiliki kesiapan menghadapi persaingan kerja. Di Indonesia, sesuai dengan ketentuan yang ditetapkan dalam Standar Nasional Pendidikan Tinggi (SN DIKTI) pada tahun 2014, setiap program studi harus dilengkapi dengan target pencapaian pembelajaran [5]. Institusi pendidikan seperti Universitas seringkali membutuhkan bentuk keputusan dalam menentukan konsentrasi yang tepat bagi mahasiswa sehingga dapat mencapai pembelajaran yang baik sesuai dengan minat mahasiswa. Keputusan ini sangat berpengaruh pada proses penanganan pemilihan jurusan alternatif, memilih jurusan yang sesuai minat akan berdampak pada fokus penelitian untuk tugas akhir mahasiswa.

Proses penentuan jurusan saat ini sebagian besar masih dilakukan dengan metode konvensional di mana proses seleksi dengan penilaian akademik sama seperti IPK. Beberapa masalah teknis yang sering terjadi adalah, dalam pelaksanaan proses seleksi akan memakan waktu lama karena masih dilakukan secara manual. Selain itu, proses seleksi juga bisa rentan terhadap kesalahan dan hambatan dalam melaporkan hasil yang mungkin berdampak pada tahap pengumuman hasil. Proses seleksi juga tidak mempertimbangkan minat mahasiswa pada jurusan.

Saat ini sistem seleksi hanya didasarkan pada penilaian akademis, tidak ada kriteria untuk menilai minat mahasiswa, sehingga dapat mempengaruhi hasil belajar mahasiswa [6]. Salah satu cara untuk menilai minat dengan mengambil tes minat (interest inventory). Tujuan dari penelitian ini adalah merancang dan membangun perangkat lunak berbasis sistem pendukung keputusan untuk menentukan jurusan mahasiswa di jurusan elektro dengan menggabungkan penilaian akademik dan penilaian minat dengan tiga kriteria penilaian, yaitu interest inventory, nilai prasyarat mata kuliah, dan IPK.

Penelitian ini menggunakan model Sistem Pendukung Keputusan (SPK). Hasil akhir dari model ini adalah sebuah data hasil proses seleksi yang akan digunakan oleh pengambil keputusan sebagai bahan pertimbangan dalam memutuskan konsentrasi yang tepat. Konsep-konsep yang ada dalam Sistem pendukung keputusan mendukung proses analisa yang ada dalam penelitian ini, sehingga pengembangan model penelitian ini menggunakan Sistem pendukung keputusan (SPK). Sistem pendukung keputusan memiliki beberapa metode dalam menemukan hasil keputusan. Salah satu metode yang di gunakan dalam sistem pendukung keputusan adalah metode FMADM.

FMADM adalah metode yang digunakan untuk mencari alternatif yang optimal dari sejumlah alternatif dengan kriteria tertentu. Inti dari FMADM adalah untuk menentukan nilai untuk setiap atribut, kemudian dilanjutkan dengan proses peringkat yang akan memilih alternatif yang sudah diberikan. Ada 3 pendekatan untuk menemukan nilai bobot atribut, yaitu pendekatan subyektif, pendekatan obyektif dan pendekatan integrasi antara subyektif \& obyektif. Setiap pendekatan memiliki kelebihan dan kekurangan. Dalam pendekatan subjektif, nilai bobot ditentukan oleh subjektivitas para pembuat keputusan, sehingga beberapa faktor dalam proses peringkat alternatif dapat ditentukan secara bebas. Sedangkan dalam pendekatan obyektif, nilai bobot dihitung secara matematis sehingga mengabaikan subjektivitas pengambil keputusan [7]. Proses dari FMADM ini dilakukan melalui 3 tahapan yaitu [8]: 
(a) Pada tahapan penyusunan komponen situasi, akan dibentuk tabel taksiran yang berisi indentifikasi alternatif dan spesifikasi tujuan, kriteria dan atribut.

(b) Pada tahapan analisis dilakukan melalui 2 langkah yaitu:

i. Mendatangkan taksiran dari besaran potensial, kemungkinan, dan ketidakpastian yang berhubungan dengan dampak-dampak yang mungkin pada setiap alternatif.

ii. Melakukan pemilihan dari preferensi pengambilan keputusan untuk setiap nilai dan ketidakpedulian pada setiap resiko yang timbul.

(c) Dan kemudian dilakukan tahap sintesis informasi.

Berdasarkan latar belakang permasalahan tersebut maka dibangunlah perangkat lunak sistem pendukung keputusan dengan metode Fuzzy Multiple Attribute Decision Making (FMADM). Sistem menggunakan tes minat yang dapat digunakan oleh mahasiswa sebagai panduan sebelum memilih bidang keahlian. Sistem ini diharapkan dapat membantu ketua program studi sebagai pengambil keputusan dalam menentukan konsentrasi yang paling sesuai dengan minat mahasiswa, dan dapat membantu proses bimbingan karir kepada mahasiswa. Penentuan jurusan yang tepat akan memiliki efek jangka panjang pada karir mahasiswa di masa depan.

\section{METODOLOGI}

Jenis penelitian ini adalah research and development (R\&D). Produk yang dihasilkan dalam penelitian ini berupa perangkat lunak (software). Produk pengembangan yang dilakukan dalam penelitian ini berupa pemilihan konsentrasi mahasiswa di Jurusan Elektro dengan interest inventory menggunakan model sistem cerdas FMADM (Fuzzy Multiple Attribute Decision Making) yang dapat membantu pengambil keputusan dalam proses penyeleksian dan sebagai tahap bimbingan karir, dengan target memberikan keputusan konsentrasi yang paling sesuai dengan minat mahasiswa dengan tujuan untuk meningkatkan hasil belajar

Metodologi penelitian dapat diilustrasikan seperti pada Gambar 1. 


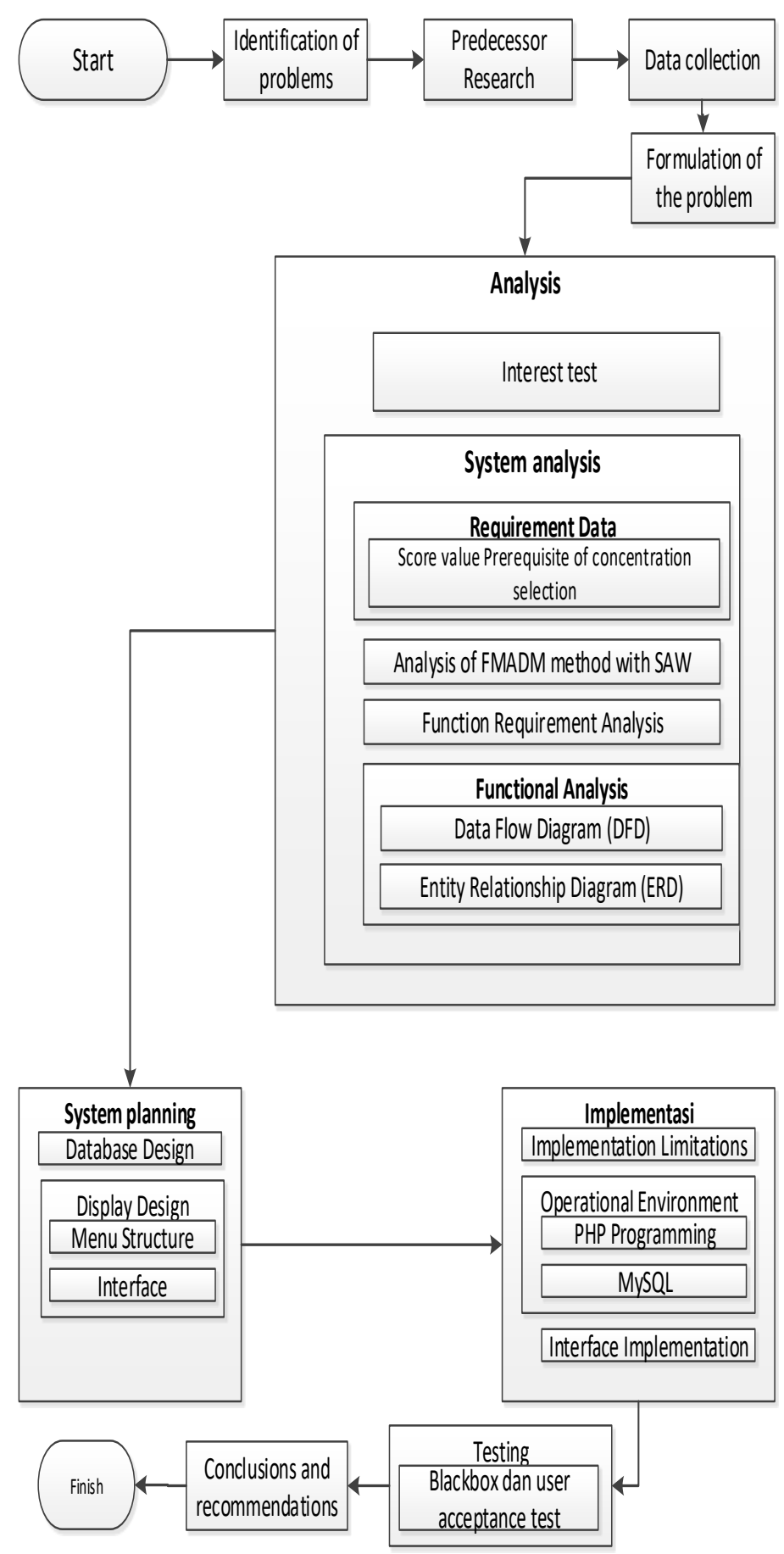

Gambar 1. Bagan metodologi penelitian

\section{HASIL DAN PEMBAHASAN}

Analisis adalah langkah pertama dalam proses mendapatkan pemahaman dengan mengidentifikasi dan menggambarkan masalah yang ada dan menentukan kebutuhan. Sedangkan desain adalah pengembangan dari masalah-masalah yang ada dalam suatu analisis yaitu membuat detail langkah-langkah kerja pada suatu analisis sehingga menjadi desain agar mudah dipahami. Analisis perangkat lunak dalam pengembangan perangkat lunak pemilihan konsentrasi mahasiswa menggunakan fuzzy multiple atribut decision making dengan metode pembobotan aditif sederhana meliputi analisis subsistem data, analisis model sistem dan analisis fungsional sistem sehingga sistem yang dibangun sesuai dengan maksud dan tujuan yang ingin dicapai dalam penelitian ini (Gambar 2).

FMADM adalah metode yang digunakan untuk mencari alternatif yang 
optimal dari sejumlah alternatif dengan kriteria. Inti dari FMADM adalah untuk menentukan nilai berat untuk setiap atribut, kemudian dilanjutkan dengan proses peringkat yang memilih alternatif yang sudah diberikan [6]. Di dalam FMADM ada beberapa komponen umum yang digunakan adalah:

(a) Alternatif yaitu objek-objek yang berbeda dan memiliki kesempatan yang sama untuk dipilih oleh pengambil keputusan.

(b) Atribut yang sering disebut sebagai karakteristik, komponen atau kriteria keputusan. Meskipun pada kebanyakan kriteria bersifat satu level, namun tidak menutup kemungkinan adanya sub-kriteria yang berhubungan dengan kriteria yang telah diberikan.

(c) Konflik antar kriteria, beberapa kriteria biasanya memiliki konflik antara satu dengan yang lainnya.

(d) Bobot keputusan (W), bobot keputusan ini menunjukkan kepentingan relatif dari setiap kriteria.

Matriks keputusan, suatu matriks keputusan $\mathrm{X}$ yang berukuran $\mathrm{m} \times \mathrm{n}$, berisi elemen $\mathrm{x}_{\mathrm{ij}}$, yang merepresentasikan rating dari alternatif $A_{i}(i=1,2, \ldots, m) m$ adalah banyaknya jumlah alternatif, terhadap kriteria $C_{j}$ $(\mathrm{j}=1,2, \ldots, \mathrm{n}), \mathrm{n}$ adalah jumlah kriteria.

Secara umum pengembangan perangkat lunak ini dibagi menjadi 3 tahap:

(a) Desain Subsistem Data

Tahap ini adalah desain analisis dari subsistem manajemen data sebelumnya. Tahap ini menggambarkan diagram konteks, diagram aliran data dan diagram hubungan entitas. dan selanjutnya akan dibuat desain kamus data.

(B) Desain Subsistem Model

Tahapan ini merupakan hasil analisis model yaitu metode yang digunakan dalam pembuatan sistem. Pada tahap ini akan dibuat perancangan model berupa flowchart sistem dan perhitungan metode FMADM dari proses penentuan peringkat urutan prioritas alternatif.

(c) Desain Subsistem Dialog

Tahap ini adalah hasil dari analisis subsistem manajemen dialog. Tahap ini akan menghasilkan struktur menu desain dan desain antarmuka (interface) sistem.

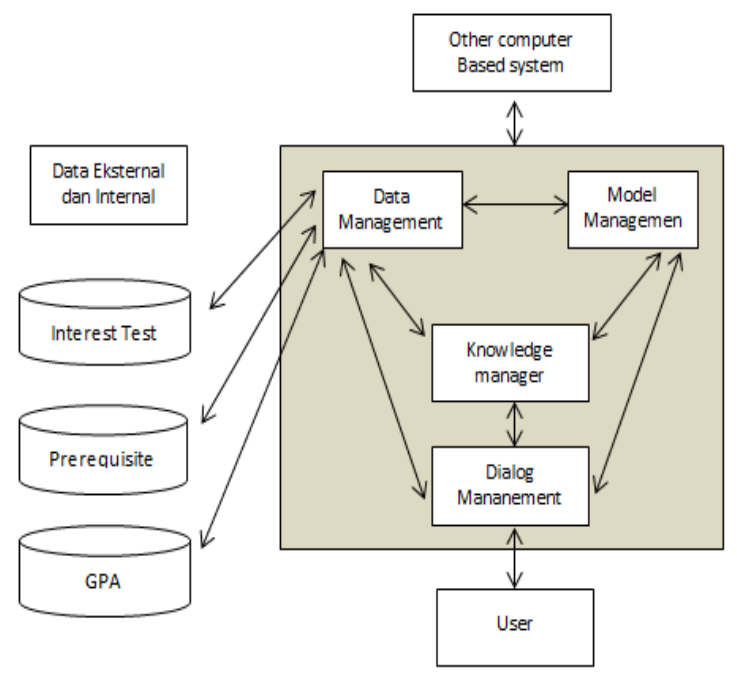

Gambar 2. Komponen sistem penentuan konsentrasi

Tes minat untuk mahasiswa mengunakan interest inventory, ada 25 tabel instrumen untuk tes minat, 2 di antaranya adalah sebagai berikut:

Tabel 1. Tabel Instrumen untuk tes minat.

\begin{tabular}{ccc}
\multicolumn{3}{c}{ A } \\
\hline NO & KEYWORDS & SCALE \\
\hline 1 & Instrumentation Measurement \\
& and Control System \\
2 & Optical Communications Network \\
3 & Electricity Weak Flow And \\
& Computer Programming. \\
4 & Energy sources \\
\hline \multicolumn{3}{|}{ B } \\
\hline NO & KEYWORDS \\
\hline 1 & Energy convertion \\
3 & Measurement And Control Of \\
4 & Chemical Reactions \\
\hline
\end{tabular}

Angka untuk Skala Kepentingan

a. Sangat Suka $=1$

b. Suka $=2$

c. Kurang Suka $=3$

d. Tidak suka $=4$.

Adapun kebutuhan data-data yang diperlukan dalam pembuatan sistem ini adalah:

1) Data Alternatif

Data alternatif berisi konsentrasi yang ada di Jurusan Elektro, yaitu:

a. Elektronika Instrumentasi

b. Telekomunikasi

c. Teknik Komputer dan Multimedia

d. Energi 
2) Data Variabel

Data variabel berisi kriteria-kriteria yang menjadi faktor penilaian dalam seleksi pemilihan konsentrasi. Kebutuhan data variabel ini adalah:

a. Nilai Mata kuliah prasyarat

b. Nilai hasil tes inventori minat. Yang didapat dari hasil inventori minat oleh mahasiswa untuk melihat kecenderungan minat dari 4 bidang konsentrasi yang ada di Jurusan Elektro

c. Nilai IPK mahasiswa

Data alternatif dan data variable ditampilkan dalam Tabel 2 dan 3:

Tabel 2. Alternatif pemilihan konsentrasi.

\begin{tabular}{cc}
\hline Alternatif & Keterangan \\
\hline A1 & Konsentrasi Eletronika \\
Instrumentasi \\
A2 & Konsentrasi Telekomunikasi \\
A3 & Konsentrasi Teknik Komputer \\
dan Multimedia \\
A4 & Konsentrasi Energi \\
\hline
\end{tabular}

Tabel 3. Kriteria pemilihan konsentrasi.

\begin{tabular}{cc}
\hline Kriteria & Keterangan \\
\hline $\mathrm{C} 1$ & Nilai IPK \\
$\mathrm{C} 2$ & Nilai Prasyarat Mata Kuliah \\
$\mathrm{C} 3$ & Nilai Inventori minat \\
\hline
\end{tabular}

Tahapan analisis kebutuhan sistem yang diperlukan dalam pembuatan pengembangan perangkat lunak ini adalah:

1) Analisis model lama

Analisis sistem lama yaitu menganalisis model yang ada saat ini.

2) Analisis model baru

Setelah mempelajari model lama, kemudian dilanjutkan dengan melakukan analisis terhadap model baru yang akan dibangun. Analisis model baru dilakukan dengan cara menganalisis komponen-komponen dari Sistem Pendukung Keputusan yang meliputi:

A. Analisis Subsistem Manajemen Data

Pada komponen ini dilakukan analisis terhadap data-data yang diperlukan untuk membangun sistem. Data-data tersebut terdiri dari data masukan dan data keluaran. Data yang diperlukan untuk sistem adalah data mahasiswa dan data kriteria yang ditetapkan.

B. Analisis Subsistem Manajemen Model Pada komponen ini dilakukan analisis terhadap model yang diterapkan FMADM dan perhitungan tes psikologi minat dengan skala ordinal. Untuk perhitungan inventori minat adalah sebagai berikut:

a. Tes diberikan kepada mahasiswa (perseorangan atau kelompok).

b. Testee (mahasiswa) membuat rangking dari daftar kata kunci bidang elektro yang tersedia dalam instrumen tes.

c. Rangking dimulai dengan nomor 1 untuk kata kunci bidang elektro yang paling disukai dalam satu kelompok.

d. Dan diakhiri dengan nomor 4 kata kunci bidang elektro yang paling tidak disukai, sesuai dengan jumlah kata kunci bidang elektro yang terdapat dalam satu kelompok.

Fuzzy Multi Attribute Decision Making (FMADM) menggunakan metode Simple Additive Weighting (SAW) yang merupakan basis dari proses pengambilan keputusan untuk menentukan alternatif terbaik. Adapun langkahlangkah perhitungan SAW adalah sebagai berikut:

a. Menginputkan data kriteria, data alternatif dan bobot kriteria.

b. Membuat matriks keputusan berdasarkan inputan awal.

c. Normalisasi matriks yang dicocokkan dengan dengan jenis atribut sehingga menghasilkan matriks ternormalisasi.

d. Mengalikan matriks ternormalisasi $\mathrm{R}$ dengan bobot kriteria yang sudah diinput.

e. Langkah akhir, preferensi tiap alternatif berdasarkan hasil perkalian matriks ternormalisasi $\mathrm{R}$ dengan bobot kriteria.

Data kriteria, data alternatif dan bobot kriteria dijabarkan dalam Tabel 4 sampai Tabel 7:

Tabel 4. Komposisi penilaian nilai mata kuliah.

\begin{tabular}{cccc}
\hline Klasifikasi & Nilai MK & $\begin{array}{c}\text { Lingu } \\
\text { istik }\end{array}$ & $\begin{array}{c}\text { Nilai } \\
\text { FMADM }\end{array}$ \\
\hline Sangat & 0 & SK & 0,2 \\
Kurang & & & \\
Kurang & 1 & K & 0,4 \\
Cukup & $2-2,3$ & $\mathrm{C}$ & 0,6 \\
Baik & $2,7-3,3$ & $\mathrm{~B}$ & 0,8 \\
Sangat Baik & $3,7-4$ & SB & 1 \\
\hline
\end{tabular}


Tabel 5. Komposisi nilai IPK.

\begin{tabular}{cccc}
\hline Klasifikasi & Nilai IPK & $\begin{array}{c}\text { Lingu } \\
\text { istik }\end{array}$ & $\begin{array}{c}\text { Nilai } \\
\text { FMADM }\end{array}$ \\
\hline Sangat & 0 & SK & 0,2 \\
Kurang & & & \\
Kurang & 1 & $\mathrm{~K}$ & 0,4 \\
\hline Cukup & $2-2,3$ & $\mathrm{C}$ & 0,6 \\
Baik & $2,7-3,3$ & $\mathrm{~B}$ & 0,8 \\
Sangat Baik & $3,7-4$ & $\mathrm{SB}$ & 1 \\
\hline
\end{tabular}

Tabel 6. Komposisi nilai minat.

\begin{tabular}{cccc}
\hline Klasifikasi & Nilai Minat & $\begin{array}{c}\text { Lingu } \\
\text { istik }\end{array}$ & $\begin{array}{c}\text { Nilai } \\
\text { FMADM }\end{array}$ \\
\hline Sangat & $>83,25$ & SK & 0,2 \\
Kurang & & & \\
Kurang & $66,76-83,25$ & $\mathrm{~K}$ & 0,4 \\
Cukup & $50,26-66,75$ & $\mathrm{C}$ & 0,6 \\
Baik & $33,76-50,25$ & $\mathrm{~B}$ & 0,8 \\
Sangat Baik & $<33,76$ & $\mathrm{SB}$ & 1 \\
\hline
\end{tabular}

Tabel 7. Rating kepentingan variabel.

\begin{tabular}{cccc}
\hline Variabel & $\begin{array}{c}\text { Nilai } \\
\text { MK }\end{array}$ & $\begin{array}{c}\text { Nilai } \\
\text { IPK }\end{array}$ & $\begin{array}{c}\text { Nilai } \\
\text { Minat }\end{array}$ \\
\hline Rating Kepentingan & 4 & 3 & 5 \\
\hline
\end{tabular}

Tingkat kepentingan setiap variabel ini dinilai dengan angka

$1-5$, yaitu:

$1=$ tidak penting

$2=$ kurang penting

$3=$ cukup penting

$4=$ penting

$5=$ sangat penting

C. Analisis Subsistem Manajemen Dialog

Pada komponen ini akan dianalisis mengenai dialog antar user dengan sistem yang struktur tampilan atau antarmuka pemakai (user interface) yang bersifat user friendly. Diagram konteks digunakan untuk menggambarkan proses kerja suatu sistem secara umum. DFD level 0 atau diagram konteks digambarkan pada Gambar 3.

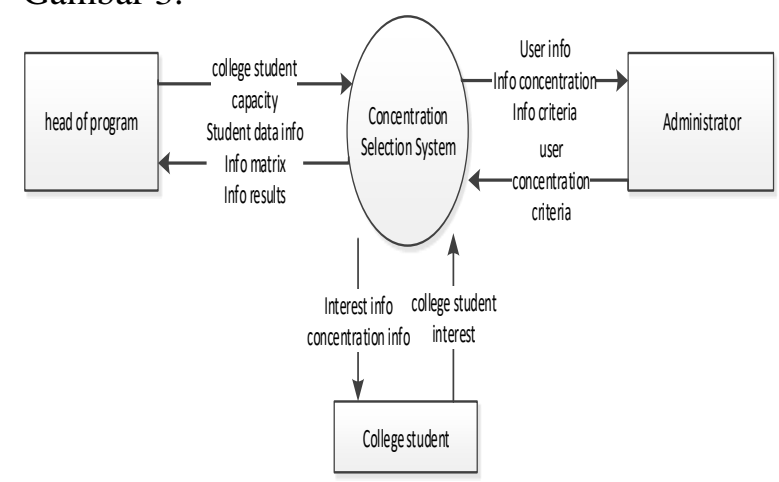

Desain Struktur Menu, Tujuan desain adalah membuat panduan desain pada tahap implementasi desain sistem yang akan dibangun. Struktur menu sistem ini dapat dilihat pada Gambar 4.

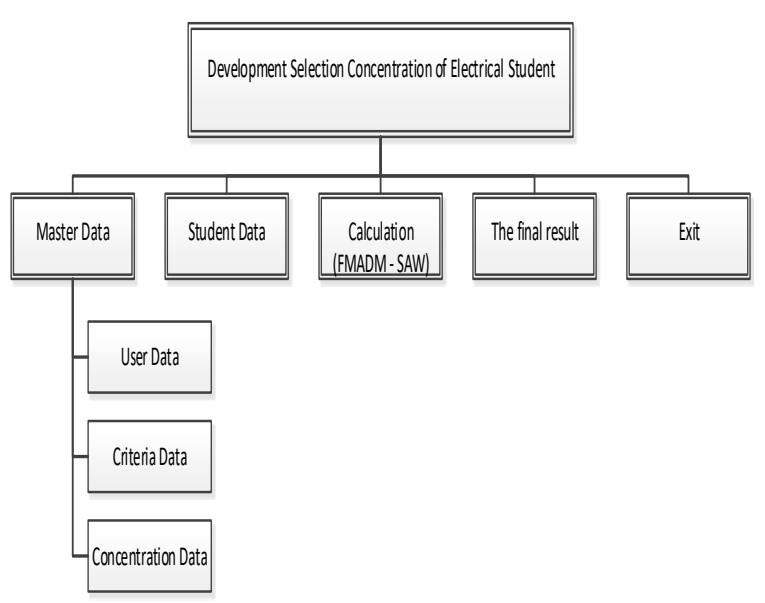

Gambar 4. Struktur menu

Tahap implementasi adalah suatu kondisi di mana sistem telah dianalisis dan dirancang siap untuk dioperasikan di bawah kondisi aktual, dari tahap implementasi ini akan diketahui tingkat keberhasilan analisis dan desain pada sistem yang akan dibangun. Implementasinya menggunakan bahasa pemrograman PHP dan MySQL. Pengguna dibagi menjadi 3 yaitu ketua prodi, admin jurusan dan mahasiswa.

Administrator (ketua prodi dan admin) memiliki hak akses penuh ke sistem, dapat menambah, mengubah, dan menghapus data master dan dapat melihat laporan hasil tes mahasiswa. Mahasiswa hanya bisa menguji minat saja. Sebelum mengakses sistem, mahasiswa terlebih dahulu mengisi data untuk mendapatkan izin masuk.

Gambar 3. Diagram konteks 


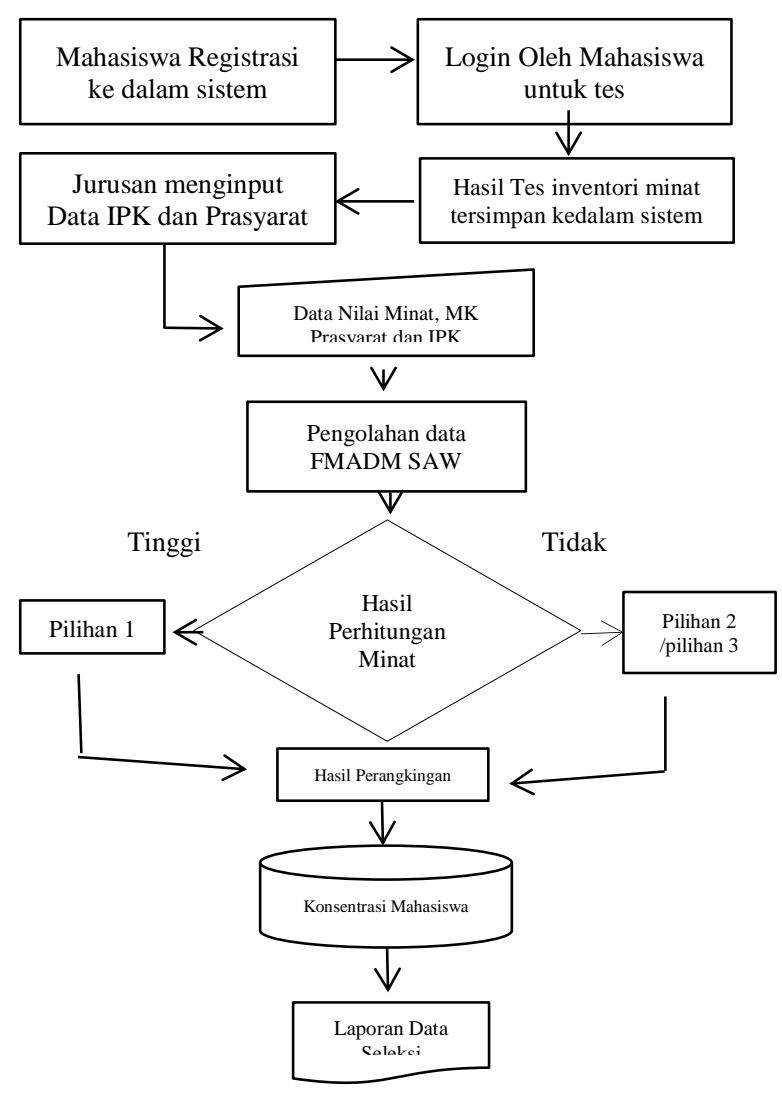

Gambar 5. Flowchart sistem

Flowchart sistem yang dikembangkan dapat dilihat pada gambar 5 .

(a) Tampilan Beranda

Sebelum mengakses sistem, Admin harus login terlebih dahulu, masukkan nama pengguna dan kata sandi. Setelah Login akan muncul halaman utama:

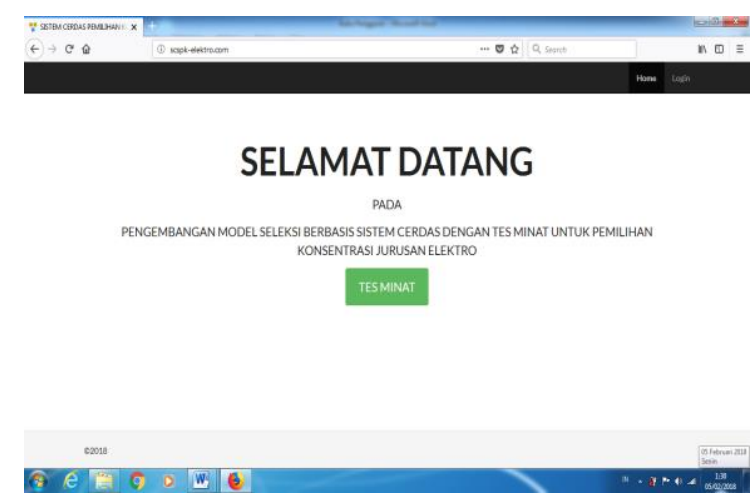

Gambar 6. Halaman utama

Submenu Pengguna adalah menu untuk mengelola data pengguna sistem, seperti menambah pengguna, melihat, memodifikasi, dan menghapus. Submenu Kriteria adalah menu untuk mengelola data kriteria, seperti menambah, melihat, memodifikasi, dan menghapus data kriteria. Submenu konsentrasi adalah menu untuk mengelola data konsentrasi seperti menambah, melihat, mengubah, dan menghapus konsentrasi. Submenu mata kuliah (MK) adalah menu untuk mengelola data mata kuliah seperti menambah, melihat, mengubah, dan menghapus kursus. Submenu Range of Values adalah menu untuk mengelola data rentang nilai fuzzy untuk nilai IPK, Subjek dan Minat seperti menambah, melihat, mengubah, dan menghapus rentang nilai.

Pada Submenu Data Siswa, sebuah menu untuk mengelola data siswa, dengan terlebih dahulu memilih tahun dan semester yang diinginkan. Administrator dapat mengisi Nilai MK prasyarat konsentrasi, Nilai IPK seperti menambah, melihat, memodifikasi, dan menghapus. Administrator dapat melihat Nilai Minat Siswa yang diperoleh dari proses tes minat yang telah dilakukan oleh siswa. Administrator dapat melakukan proses peringkat untuk melihat peringkat nilai siswa. Di bawah ini akan ditampilkan berbagai proses yang telah dijelaskan di atas dalam bentuk gambar. Sub-menu Perhitungan Hasil dan Pemeringkatan: 


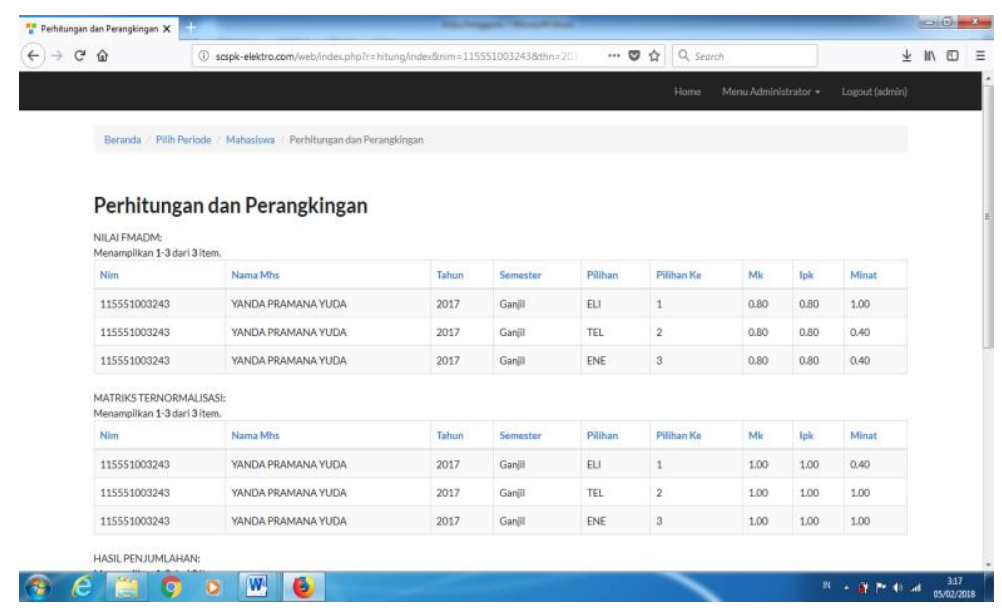

Gambar 7. Halaman perhitungan nilai

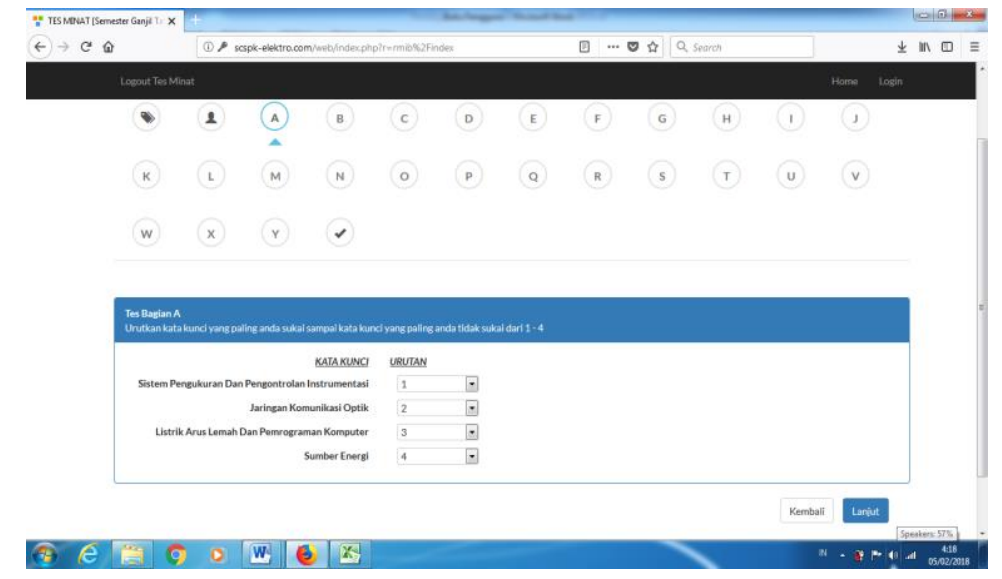

Gambar 8. Halaman tes minat mahasiswa

Setelah pengembangan perangkat lunak, maka dilakukan pengujian perangkat lunak yang telah dibuat. Pengujian diperlukan sebagai ukuran agar perangkat lunak dapat berjalan sesuai dengan tujuannya. Dalam pengujian ini ada beberapa hal yang dijadikan rujukan, yaitu: Pengujian perangkat lunak (blackbox) dan uji penerimaan pengguna (uses acceptance test).

\section{PENUTUP}

Setelah menyelesaikan beberapa tahap penelitian dalam pengembangan aplikasi pemilihan konsentrasi ini, beberapa kesimpulan dapat ditarik:

1. Perangkat lunak pemilihan konsentrasi menggunakan metode Fuzzy Multiple Attribute Decision Making berhasil dibangun dan mampu memberikan keputusan cepat untuk menentukan konsentrasi terbaik bagi mahasiswa.

2. Berdasarkan uji black box dan UAT ada 15 pertanyaan dengan 4 pengguna perangkat lunak yaitu ketua prodi dan staf administrasi dan 19 pertanyaan untuk 6 siswa. Dengan rincian perhitungan persentase sebagai berikut: kuesioner 1 dengan ketua prodi dan staf administrasi adalah 85,67\%, dan kuesioner 2 dengan siswa adalah $86,14 \%$. Dengan demikian, dapat disimpulkan bahwa perangkat lunak dapat diterima dengan baik oleh pengguna.

\section{DAFTAR PUSTAKA}

[1] E. B. Hurlock, Developmental Psychology An Approach Throughout the Life Span, 5th ed. Jakarta: Erlangga, 1999.

[2] Munandir, Program Bimbingan Karier di Sekolah. Jakarta: Dikti Depdikbud, 1996.

[3] C. C. Vasilescu, A. Moraru, and N. I. Sava, "The Relationship between Career Interests and Academic Major: A Comparative Analysis," Procedia - Soc. Behav. Sci., vol. 187, pp. 559-564, May 
2015.

[4] P. R. Subramaniam, "Motivational Effects of Interest on Student Engagement and Learning in Physical Education : A Review," Int J Phys Educ., vol. 46, no. 2, pp. 11-20, 2009.

[5] Belmawa Ristek Dikti, "Panduan Penyusunan Capaian Pembelajaran," 2016. [Online]. Available: http://belmawa.ristekdikti.go.id/dev/wpcontent/uploads/2015/11/6A-PanduanPenyusunan-CP.pdf.

[6] J. L. HOLLAND and R. C. NICHOLS, "Explorations of a Theory of Vocational Choice: III. A Longitudinal Study of Change in Major Field of Study," Pers. Guid. J., vol. 43, no. 3, pp. 235-242, Nov. 1964.

[7] F. N. Khasanah, A. E. Permanasari, and S. Suning Kusumawardani, "Fuzzy MADM for major selection at senior high school," in 2015 2nd International Conference on Information Technology, Computer, and Electrical Engineering (ICITACEE), 2015, pp. 41-45.

[8] Y. MZ, "Sistem Pendukung Keputusan Konsentrasi dan Peminatan Prodi Teknik Informatika Universitas Janabadra Yogyakarta," Creat. Inf. Technol. J., vol. 3, no. 4, p. 307, 2016.

\section{Hak Cipta}

Semua naskah yang tidak diterbitkan, dapat dikirimkan di tempat lain. Penulis bertanggung jawab atas ijin publikasi atau pengakuan gambar, tabel dan bilangan dalam naskah yang dikirimkannya. Naskah bukanlah naskah jiplakan dan tidak melanggar hak-hak lain dari pihak ketiga. Penulis setuju bahwa keputusan untuk menerbitkan atau tidak menerbitkan naskah dalam jurnal yang dikirimkan penulis, adalah sepenuhnya hak Pengelola. Sebelum penerimaan terakhir naskah, penulis diharuskan menegaskan secara tertulis, bahwa tulisan yang dikirimkan merupakan hak cipta penulis dan menugaskan hak cipta ini pada pengelola. 